\begin{tabular}{ccc} 
JURNAL BIOTERDIDIK: WAHANA EKSPRESI ILMIAH & \\
\hline & $\begin{array}{c}\text { e-ISSN: } \\
2621-5594 \\
\text { p-ISSN: } \\
\text { Vol. 9 No. 3, Desember 2021, page. 217-225 } \\
\text { Jurnal Eioterdidilik }\end{array}$ & \\
\hline
\end{tabular}

\title{
Pengaruh Pembelajaran TGT (Teams Games Tournament) Dengan Media Explosion Box Pada Materi Sistem Ekskresi Manusia Terhadap Hasil Belajar Siswa
}

\author{
Nadila Husnah*, Kartika Manalu, Khairuddin \\ Universitas Islam Negeri Sumatera Utara \\ *e-mail: husnahnadila@gmail.com
}

Received: November 5, 2021 Accepted: December 24, $2021 \quad$ Online Published: December 30, 2021

\begin{abstract}
The Effect Of TGT (Teams Games Tournaments) Learning With Explosion Box Media On Human Excretion System On Learning Outcomes Of Students. This reserch aims to determine the effect of TGT (Team Games Tounament) learning with the explosion box media on the human excretion system material on student learning outcomes of class XI MA Al-Mukhlishin Batu Bara. This type of research is quasi-experimental or quasi-experimental. The instrument in this study was in the form of an objective test or multiple choice of 20 questions. Data analysis in this study was a paired simple t-test with the help of Statistical Product and Service Solutions (SPSS) software version 22. By looking at the significance value, namely if Sig (2-tailed) <0.05. as for the results found is the sig value. 2-tailed $0.00<0.05$ with a value of $t$-count $>t$-table, namely 23.38> 2.01, which means that $\mathrm{HO}$ is rejected, and Ha is accepted. This shows that there is an effect of TGT (team games tournaments) learning with the media explosion box on the human excretion system material on the learning outcomes of students of class XI IPA Ma Al-Mukhlishin Batu Bara.
\end{abstract}

Keywords: Excretion system, learning outcomes, TGT with Explosion Box

\begin{abstract}
Abstrak: Pengaruh Pembelajaran Tgt (Teams Games Tournament) Dengan Media Explosion Box Pada Materi Sistem Ekskresi Manusia Terhadap Hasil Belajar Siswa. Penelitian ini bertujuan untuk mengetahui pengaruh pembelajaran TGT (Team Games Tounament) dengan media explosion box pada materi sistem ekskresi manusia terhadap hasil belajar siswa kelas XI MA Al-Mukhlishin Batu Bara. jenis penelitian ini kuasi experimen atau eksperimen semu. Instrumen dalam penelitian ini dalam bentuk tes objektif atau pilihan berganda sebanyak 20 soal. Analisis data pada penelitian ini adalah uji paired simple t-test dengan bantuan sofware Statistical Product and Service Solutions (SPSS) versi 22. dengan melihat nilai signifikansinya yaitu jika Sig (2-tailed) $<0,05$. adapun hasil yang ditemukan adalah nilai sig. 2tailed $0,00<0,05$ dengan nilai t-hitung $>$ t-tabel yaitu 23,38 $>2,01$ yang berarti $\mathrm{H} 0$ ditolak dan Ha diterima. Hal ini menunjukkan bahwa ada pengaruh pembelajaran TGT (teams games tournaments) dengan media explosion box pada materi sistem ekskresi manusia terhadap hasil belajar siswa kelas XI IPA Ma Al-Mukhlishin Batu Bara.
\end{abstract}

Kata kunci: hasil belajar, TGT dengan Explosion Box, sistem ekskresi 


\section{PENDAHULUAN}

Pendidikan di Indonesia dalam Undangg-undang Sistem Pendidikan Nasional No.2 Tahun 2003 bertujuan untuk mengembangkan potensi peserta didik agar dapat menjadi manusia yang beriman, bertakwa kepada Tuhan Yang Maha Esa, berakhlak mulia, sehat, berilmu, cakap dan kreatif agar menjadi warga Negara yang demokratis serta bertanggung jawab (Ayi, 2010)

Mengingat tentang ilmu, sebenarnya sudah menjadi perintah Allah untuk tetap menuntut, dan mempelajarinya agar kita dapat membedakan perkara yang baik dan perkara yang buruk untuk tetap bertaqwa kepada Allah dan beriman kepadaNya. sebagaimana dalam firman Allah dalam surah Al-Hud ayat 24 :

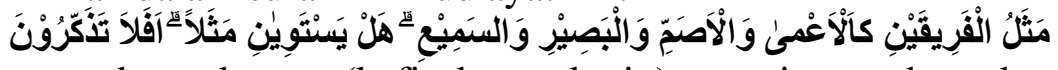

Artinya : Perumpamaan dua golongan (kafir dan mukmin) seperti orang buta dan orang tuli dengan orang yang dapat melihat dan yang dapat mendengar. samakah kedua golongan itu? apakah kamu tidak mengambil pelajaran? (Departemen Agama RI, 2020).

Dalam dunia pendidikan nasional, tingkat keberhasilan proses belajar siswa dapat dilihat dari nilai akhir belajarnya. Hasil belajar adalah prestasi yang telah dicapai atau diperoleh anak berupa nilai mata pelajaran. ditambahkan bahwa hasil belajar merupakan prestasi yang mengakibatkan perubahan dalam diri individu sebagai hasil dari aktivitas dalam belajar. Setelah menelusuri uraian diatas, maka dapat dipahami bahwa hasil belajar adalah perolehan atau taraf kemampuan yang telah dicapai siswa setelah mengikuti proses belajar mengajar dalam waktu tertentu baik berupa perubahan tingkah laku, keterampilan dan pengetahuan dan kemudian akan diukur dan dinilai yang kemudian diwujudkan dalam angka atau pernyaraan. (Syarifuddin, 2019)

Hasil wawancara terhadap guru biologi Ma Al-Mukhlishin Batu Bara pada hari Kamis tanggal 27 Februari 2020 sebagai observasi awal, diketahui bahwa nilai Kriteria Ketuntasan Minimal (KKM) sekolah tersebut adalah 75 dan diperoleh data bahwa hasil belajar siswa pada materi sistem ekskresi manusia hanya sebanyak 50\% dari 80 siswa yang mencapai Kriteria Ketuntasan Minimal (KKM). Untuk mengatasi masalah tersebut guru mata pelajaran biologi biasanya membuat remedial untuk memperbaiki nilai siswa yang masih di bawah KKM.

Hasil observasi yang dilakukan pada hari rabu sampai dengan hari sabtu tanggal 26-29 Februari 2020 di Ma Al-Mukhlishin Batu Bara ditemukan hanya sebagian siswa yang memperhatikan guru pada saat guru menjelaskan mata pelajaran Biologi. Hal ini dikarenakan guru masih menggunakan metode pembelajaran yang masih bersifat konvensional atau ceramah. Metode konvensional ini adalah metode yang membuat guru harus aktif dalam proses pembelajaran dan siswa hanya berperan sebagai pendengar materi pembelajaran yang disampaikan sehingga dapat mengakibatkan siswa cendrung pasif (kurang aktif) pada proses pembelajaran. Hal ini yang menyebabkan siswa merasa jenuh ketika berlangsung mata pelajaran Biologi. Siswa jarang mendapat kesempatan bertanya atau bertukar pikiran sesama mereka di dalam kelas dan siswa juga belum dapat menjawab secara lancar pertanyaan yang diajukan oleh guru biologi secara lisan karena sikap siswa yang masih kurang memperhatikan guru pada saat pembelajaran dimulai.

Berdasarkan uraian di atas maka perlu dipertimbangkan penerapan metode pembelajaran lain yang dapat meningkatkan keaktifan siswa dalam pembelajaran biologi khususnya pada materi sistem ekskresi manusia. Materi sistem ekskresi manusia menuntut siswa untuk memahami struktur, fungsi organ, proses serta kelainan yang terjadi pada sistem ekskresi manusia. Metode pembelajaran yang dapat diterapkan salah satunya adalah metode pembelajaran kooperatif tipe TGT (Teams Games Tournaments). 
Metode pembelajaran TGT (Teams Games Tournaments) adalah bagian dari pembelajaran kooperatif. Pembelajaran kooperatif adalah suatu model pembelajaran dimana siswa belajar dan bekerja dalam kelompok-kelompok kecil secara kolaboratif yang anggotanya 4-6 orang dengan struktur kelompok heterogen. Pembelajaran kooperatif merupakan suatu cara pendekatan atau serangkaian strategi yang khusus dirancang untuk memberi dorongan kepada peserta didik agar bekerja sama selama proses pembelajaran. (Tukiran, 2017)

Metode pembelajaran kooperatif tipe Team Games Tournament adalah salah satu metode pembelajaran kooperatif yang menjadikan siswa sebagai pusat kegiatan. Penerapan model pembelajaran Team Games Tournament adalah salah satu tipe atau model pembelajaran kooperatif yang mudah diterapkan, melibatkan aktivitas seluruh siswa tanpa harus ada perbedaan status, melibatkan siswa sebagai tutor sebaya dan mengandung unsur permainan dan reinforcement yang bersifat tidak membosonkan. Aktivitas belajar dengan permainan yang dirancang dalam pembelajaran kooperatif tipe Team Games Tournament memungkinkan siswa dapat belajar lebih rileks disamping menumbuhkan tanggung jawab, kejujuran, kerja sama yang tidak dapat membedakan status.(Ulfa, 2017)

Proses pembelajaran akan lebih efektif dan efisien jika disampaikan dengan media pembelajaran. Salah satu media pembelajaran yang dapat digunakan adalah explosion box.

Explosion box sama artinya dengan magic box (kotak misteri) menurut Laili,dkk., magic box diterjemahkan ke dalam bahasa Indoneisa adalah kotak ajaib atau kotak misteri. Magic box adalah kotak atau kardus yang ukurannya dapat disesuaikan dengan kebutuhan dan tidak tembus pandang. Dinamakan magic box (kotak misteri) karena terbuat dari kardus yang berbentuk kotak, sedangkan misteri karena pada saat kotaknya ditutup, siswa tidak mengetahui benda apa yang ada di dalam kotak, makanya dinamakan kotak ajaib atau misteri.( Sinamora, 2019)

Explosion box merupakan media tiga dimensi yang lebih umum digunakan sebagai kotak kejutan untuk hadiah istimewa di hari spesial. Kejutan dalam kotak tersebut memuat gambar, foto, ungkapan atau kemasan yang dikemas dalam kotak dengan tampilan yang unik. Lebih dari sekedar kejutan dan hadiah, dewasa ini beberapa akademisi telah meneliti dan mengembangkan explosion box sebagai media edukasi. Waladiyah (2018) menyatakan bahwa Explosion box merupakan media cetak yang berisi tulisan, teks, atau gambar, media tersebut mampu meningkatkan literasi siswa kelas VII SMPN 26 surabaya. (Fitriya, 2019)

Dengan media explosion box dapat mempermudah guru dalam menyampaikan materi khususnya pada materi sistem eksresi manusia. Dimana explosion box adalah sebuah media yang didalamnya berisi tulisan, gambar (foto) yang unik sehingga dapat menarik perhatian siswa dalam proses pembelajaran.

Penerapan pembelajaran TGT (Teams Games Tournaments) dengan media explosion box dapat meningkatkan aktivitas belajar siswa. Siswa tidak merasa jenuh pada saat pembelajaran biologi khususnya pada materi sistem ekskresi manusia.

Berdasarkan latar belakang masalah dan gejala diatas, peneliti tertarik untuk melakukan penelitian yang berjudul "Pengaruh Pembelajaran Tgt (Teams Games Tounaments) Dengan Media Explosion Box Pada Materi Sistem Ekskresi Manusia Terhadap Hasil Belajar Siswa Kelas Xi Ipa Ma Al-Mukhlishin Batu Bara"

\section{METODE}


Jenis Penelitian ini adalah penelitian kuantitatif. Desain yang digunakan dalam adalah kuasi experimen atau eksperimen semu. Desain quasi experimen ini dipilih secara the nonrandomized control group pretest posttest design.

Tabel 1. Desain Penelitian

\begin{tabular}{llll}
\hline Kelompok (kelas) & Pretest & Perlakuan & Post-test \\
\hline E & $\mathrm{Y}_{1}$ & $\mathrm{X} 1$ & $\mathrm{Y}_{2}$ \\
\hline $\mathrm{K}$ & $\mathrm{Y}_{1}$ & $\mathrm{X} 2$ & $\mathrm{Y}_{2}$ \\
\hline
\end{tabular}

Keterangan :

$\mathrm{E} \quad=$ Kelas eksperimen

$\mathrm{K} \quad=$ Kelas kontrol

$\mathrm{Y}_{1} \quad=$ Hasil pretets siswa pada kelas eksperimen dan kontrol

$\mathrm{Y}_{2}=$ Hasil post-test siswa pada kelas eksperimen dan kontrol

$\mathrm{X} 1=$ Perlakuan eksperimen menggunakan pembelajaran TGT (Teams Games Tournaments)

$\mathrm{X} 2=$ Perlakuan pada kelas kontrol menggunakan pembelajaran konvensional.

Populasi dan sampel ini adalah seluruh dalam penelitian ini adalah seluruh siswa kelas XI IPA sebanyak 83 siswa yang terdiri dari dua kelas yaitu kelas XI IPA $1=43$ siswa dan XI IPA 2= 40 siswa. Teknik pengumpulan data yang digunakan dalam penelitian ini adalah teknik tes dalam bentuk objektif. tes ini adalah berupa tes pilihan berganda yang mempunyai option a, b, c, d dan e adalah salah satu jawaban yang benar. Tes ini diberikan pada kelas eksperimen dan kontrol dan dilakukan melalui uji pre-test dan post-test untuk melihat kemampuan kognitif sebagai hasil belajar siswa. Untuk melihat soal bersifat layak atau tidak terlebih dahulu divalidasi berdasarkan ketentuan dari uji validasi, adapun kriteria valid atau tidaknya butir soal dilakukan dengan cara membandingkan nilai r-hitung dengan r-tabel. Berdasarkan uji validasi soal ditemukan terdapat 13 soal yang tidak valid atau tidak dapat digunakan pada penelitian karena $\mathrm{r}$ hitung < r-tabel, dan terdapat 37 soal yang valid karena r-hitung > r-tabel. Meskipun demikian soal yang digunakan pada saat penelitian hanya sebanyak 20 soal. Setelah melakukan penelitian data dianalisis menggunakan uji normaltas, homogenitas, dan uji hipotesis.

\section{HASIL DAN PEMBAHASAN}

Penelitian ini dilakukan di Madrasah Aliyah Al-Mukhlishin Batu Bara Jln. Rahmadsyah Desa Lalang, Kecamatan Tanjung Tiram, Kabupaten Batu Bara. Tujuan penelitian ini adalah untuk mengetahui pengaruh pembelajaran TGT (Team Games Tounament) dengan media explosion box pada materi sistem ekskresi manusia terhadap hasil belajar siswa kelas XI MA Al-Mukhlishin Batu Bara. Berdasarkan hasil penelitian didapatkan hasil pre-test dan post-test siswa yang disajikan pada Tabel 2 deskriptif statistic. Berdasarkan Tabel 2 nilai rata-rata pre-test dan post-test siswa pada kelas ekperimen dan kelas kontrol dapat dilihat pada histogram Gambar 1.

Tabel 2. Deskriptif statistik 


\begin{tabular}{|l|r|r|r|r|r|}
\hline \multicolumn{7}{|c|}{ Descriptive Statistics } \\
\hline $\begin{array}{l}\text { Hasil Belajar } \\
\text { Siswa }\end{array}$ & $\mathrm{N}$ & Minimum & Maximum & Mean & $\begin{array}{c}\text { Std. } \\
\text { Deviation }\end{array}$ \\
\hline $\begin{array}{l}\text { PreTest } \\
\text { Eksperimen }\end{array}$ & 43 & 0 & 45 & 22,56 & 11,566 \\
\hline $\begin{array}{l}\text { PostTest } \\
\text { Eksperimen }\end{array}$ & 43 & 50 & 100 & 81,51 & 14,701 \\
\hline PreTest Kontrol & 40 & 0 & 45 & 23,75 & 11,477 \\
\hline $\begin{array}{l}\text { PostTest } \\
\text { Kontrol }\end{array}$ & 40 & 40 & 95 & 70,37 & 16,771 \\
\hline $\begin{array}{l}\text { Valid N } \\
\text { (listwise) }\end{array}$ & 40 & & & & \\
\hline
\end{tabular}

Berdasarkan histogram diatas diatas dapat diketahui bahwa rata-rata pre-test hasil belajar siswa pada kelas ekperimen 22,56 lebih rendah daripada rata-rata pre-test kelas kontrol yaitu 23,75. rata-rata post-test hasil belajar siswa pada kelas ekperimen 81,51 lebih tinggi daripada post-test kelas kontrol yaitu 70,37. Demikian dapat diketahui bahwa pada kelas ekperimen yang dibelajarkan dengan pembelajaran TGT (Teams Games Tournaments) dengan media explosion box dan pada kelas kontrol yang dibelajarkan dengan pembelajaran konvensional meningkat, hal ini dilihat dari nilai pre-test ke nilai post-test siswa. nilai post-test pada setiap pembelajaran lebih tinggi daripada nilai pretest siswa, dan nilai post-test siswa yag dibelajarkan dengan pembelajaran TGT (Teams Games Tournaments) dengan media explosion box yaitu pada kelas eksperimen lebih tinggi daripada nilai post-test siswa yang dibelajarkan dengan pembelajaran konvensional yaitu pada kelas control.

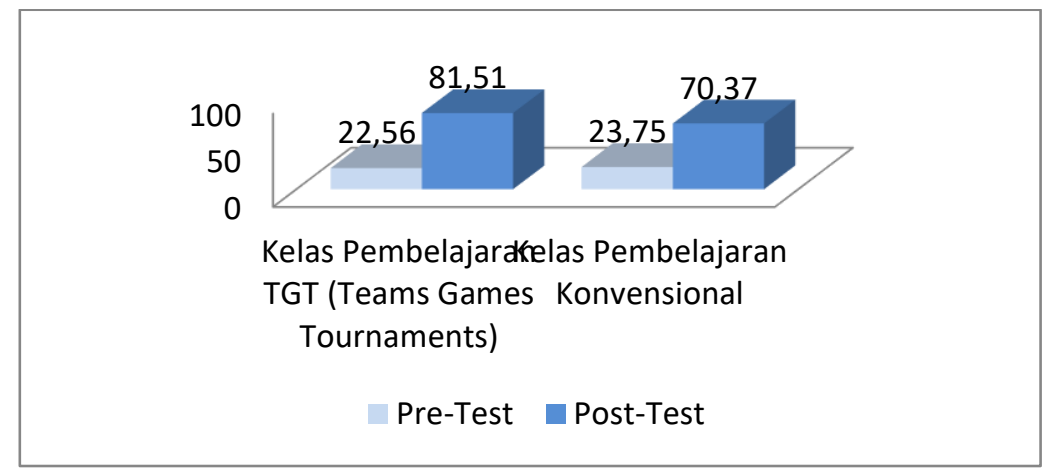

Gambar 1. Histogram rata-rata pre-test dan post-test siswa kelas XI IPA

Selanjutnya perbandingan nilai rata-rata post-test siswa pada kelas eksperimen yang dibelajarkan dengan pembelajaran TGT (Teams Games Tournaments) dengan media explosion box dengan kelas kontrol yang dibelajarkan dengan pembelajaran konvensional untuk setiap indikatornya dapat dilihat pada Tabel 3. Dari Tabel 3 dapat dilihat pada histogram perbandingan nilai rata-rata post-test siswa pada Gambar 2.

Tabel 3. Perbandingan Rata-rata Post-Test Siswa Setiap Indikator 


\begin{tabular}{rlcc}
\hline No & \multicolumn{1}{c}{ Indikator } & \multicolumn{2}{c}{ Rata-rata Post Tes } \\
\cline { 3 - 4 } & & Eksperimen & Kontrol \\
\hline $\mathbf{1}$ & C1 (pengetahuan) & 89,3 & 85,5 \\
\hline $\mathbf{2}$ & C2 (pemahaman) & 84,8 & 74,3 \\
\hline $\mathbf{3}$ & C3 (aplikasi) & 82,7 & 68,2 \\
\hline $\mathbf{4}$ & C4 (analisis) & 77,4 & 66,5 \\
\hline $\mathbf{5}$ & C5 (evaluasi) & 73,4 & 59 \\
\hline $\mathbf{6}$ & C6 (kreasi) & 70,9 & 55 \\
\hline
\end{tabular}

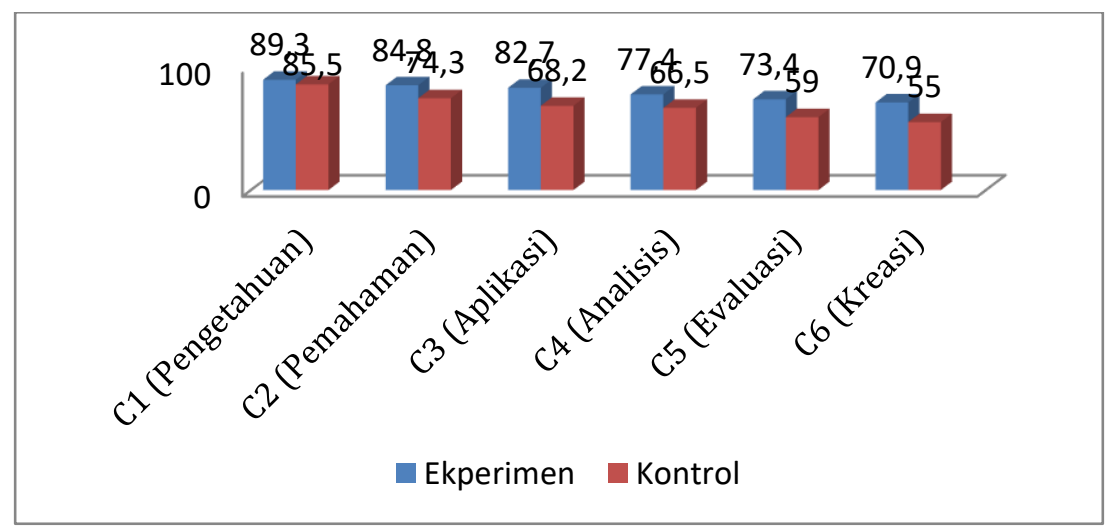

Gambar 2. Histogram perbandingan nilai rata-rata post-test siswa setiap indikator.

Dari gambar histogram diatas dapat diketahui bahwa nilai post-test siswa setiap indikator pada kelas ekperimen yang dibelajarkan dengan pembelajaran TGT (Teams Games Tournaments) dengan media explosion box lebih tinggi dari kelas kontrol yang dibelajarkan dengan pembelajaran konvensional. hal ini dapat dijabarkan pada nilai post test siswa pada setiap indikator yaitu C1 (Pengetahuan) pada kelas ekperimen 89,3 dengan kategori hasil belajar baik sekali dan pada kelas kontrol 85,5 termasuk kategori hasil belajar baik sekali. C2 (pemahaman). pada kelas ekperimen 84,8 termasuk kategori hasil belajar baik sekali, dan pada kelas kontrol 74,3 termasuk kategori hasil belajar baik. C3 (aplikasi) pada kelas ekperimen 82,7 termasuk kategori hasil belajar baik sekali, dan pada kelas kontrol 68,2 termasuk kategori hasil belajar baik. C4 (analisis) pada kelas eksperimen 77,4 termasuk kategori hasil belajar baik, dan pada kelas kontrol 66,5 termasuk kategori hasil belajar baik. C5 (evaluasi) pada kelas eksperimen 73,4 termasuk kategori hasil belajar baik dan pada kelas kontrol 59 termasuk kategori hasil belajar cukup. C6 (kreasi) pada kelas eksperimen 70,9 termasuk kategori baik dan pada kelas kontrol 55 termasuk kategori cukup.

Setelah data ditemukan, maka selanjutnya dilakukan uji normalitas (Tebel 4), uji homogenitas (Tabel 5) dan uji hipotesis (Tabel 6). Berdasarkan tabel diatas dapat diketahui bahwa hasil belajar siswa berdistribusi normal. Hal ini dapat dilihat dari hasil pre-test dan post-test siswa pada kelas eksperimen dan kelas kontrol. nilai sign 0,54 > 0,05 pre-test siswa pada kelas ekperimen, sign $0,12>0,05$ post-test siswa pada kelas ekperimen, sign 0,49 pre-test siswa pada kelas kontrol, sign 0,11>0,05 post-test siswa pada kelas kontrol. 


\begin{tabular}{|c|c|c|c|c|c|}
\hline \multicolumn{6}{|c|}{ One-Sample Kolmogorov-Smirnov Test } \\
\hline & & $\begin{array}{c}\text { PreTest } \\
\text { Eksperimen }\end{array}$ & $\begin{array}{c}\text { PostTest } \\
\text { Eksperimen }\end{array}$ & $\begin{array}{l}\text { PreTest } \\
\text { Kontrol }\end{array}$ & $\begin{array}{l}\text { PostTest } \\
\text { Kontrol }\end{array}$ \\
\hline $\mathrm{N}$ & & 43 & 43 & 40 & 40 \\
\hline \multirow{2}{*}{$\begin{array}{l}\text { Normal } \\
\text { Parameters }^{\mathrm{a}, \mathrm{b}}\end{array}$} & Mean & 22,56 & 81,51 & 23,75 & 70,38 \\
\hline & $\begin{array}{l}\text { Std. } \\
\text { Deviation }\end{array}$ & 11,566 & 14,701 & 11,477 & 16,771 \\
\hline Most & Absolute &, 118 &, 175 & 127 &, 183 \\
\hline Extreme & Positive &, 115 & 104 & 127 &, 145 \\
\hline Differences & Negative &,- 118 &,- 175 &,- 118 &,- 183 \\
\hline \multicolumn{2}{|c|}{ Test Statistic } &, 118 &, 175 &, 127 &, 183 \\
\hline \multicolumn{2}{|c|}{ Asymp. Sig. (2-tailed) } & $144^{\mathrm{c}}$ &, $002^{\mathrm{c}}$ & $103^{\mathrm{c}}$ &, $002^{\mathrm{c}}$ \\
\hline \multicolumn{2}{|c|}{ Exact Sig. (2-tailed) } & ,543 &, 126 & ,498 & , 119 \\
\hline \multicolumn{2}{|c|}{ Point Probability } & ,000 & ,000 & ,000 &, 000 \\
\hline \multicolumn{6}{|c|}{ a. Test distribution is Normal. } \\
\hline \multicolumn{6}{|c|}{ b. Calculated from data. } \\
\hline \multicolumn{6}{|c|}{ c. Lilliefors Significance Correction. } \\
\hline
\end{tabular}

Tabel 5. Uji Homogenitas

\begin{tabular}{|c|c|c|c|c|c|}
\hline \multicolumn{6}{|c|}{ Test of Homogeneity of Variance } \\
\hline & & $\begin{array}{l}\text { Levene } \\
\text { Statistic }\end{array}$ & df1 & $\mathrm{df} 2$ & Sig. \\
\hline \multirow{4}{*}{$\begin{array}{l}\text { Hasil } \\
\text { Belajar } \\
\text { Siswa }\end{array}$} & Based on Mean & 2,510 & 1 & 81 & , 117 \\
\hline & Based on Median & 2,908 & 1 & 81 & ,092 \\
\hline & $\begin{array}{l}\text { Based on Median and } \\
\text { with adjusted df }\end{array}$ & 2,908 & 1 & $\begin{array}{r}77,65 \\
9 \\
\end{array}$ & ,092 \\
\hline & Based on trimmed mea & 2,651 & 1 & 81 & ,107 \\
\hline
\end{tabular}

Berdasarkan hasil uji homogenitas hasil belajar siswa pada tabel diatas menunjukkan bahwa signifikansinya adalah $0,11>0,05$ yang berarti sampel berasal dari populasi yang variansinya homogen.

Berdasarkan hasil uji hipotesis hasil belajar siswa pada tabel diatas menunjukkan bahwa nilai sig. 2-tailed $0,00<0,05$ dengan nilai t-hitung $>$ t-tabel yaitu 23,38 $>2,01$ yang berarti $\mathrm{H} 0$ ditolak dan Ha diterima. Maka dengan demikian terdapat pengaruh pembelajaran TGT (Teams Games Tournaments) dengan media explosion box pada materi sistem ekskresi manusia terhadap hasil belajar siswa.

Dari hasil uji hipotesis penelitian ini diketahui bahwa hasil belajar siswa pada kelas ekperimen yang dibelajarkan dengan pembelajaran TGT (Teams Games Tournaments) dengan media explosion box lebih tinggi daripada kelas kontrol yang dibelajarkan dengan pembelajaran konvensional. Hal ini dilihat pada proses pembelajaran, kelas ekperimen yang dibelajarkan dengan TGT (Teams Games Tournaments) dengan media explosion box dimana siswa lebih cendrung aktif pada saat pembelajaran dibandingkan dengan pembelajaran konvensional. Sebagaimana dalam penelitian membuktikan bahwa pada pembelajaran TGT aktivitas belajar siswa lebih meningkat karena adanya interaksi dan saling membantu antara siswa yang menguasai konsep dan yang kurang menguasai konsep dalam proses pembalajaran (Yunus, 2017), sehingga pada setiap pertemuan siswa terlihat senang dan menimbulkan semangat belajar, siswa dirangsang berperan lebih aktif 
untuk menciptakan situasi belajar yang kondusif agar siswa termotivasi untuk menemukan pengetahuan dan memahami dengan baik materi pembelajaran yang diberikan sehingga mendapatkan hasil belajar yang maksimal. (Yunus, 2017).

Tabel 6. Uji Hipotesis

\begin{tabular}{|c|c|c|c|c|c|c|c|c|c|}
\hline \multicolumn{10}{|c|}{ Paired Samples Test } \\
\hline & & \multicolumn{5}{|c|}{ Paired Differences } & \multirow[b]{3}{*}{$\mathrm{T}$} & \multirow[b]{3}{*}{$\mathrm{df}$} & \multirow[b]{2}{*}{$\begin{array}{l}\text { Sig. } \\
(2- \\
\text { tailed }\end{array}$} \\
\hline & & \multirow[b]{2}{*}{ Mean } & \multirow{2}{*}{$\begin{array}{l}\text { Std. } \\
\text { Devi } \\
\text { ation }\end{array}$} & \multirow{2}{*}{$\begin{array}{l}\text { Std. } \\
\text { Error } \\
\text { Mean }\end{array}$} & \multicolumn{2}{|c|}{$\begin{array}{l}95 \% \text { Confidence } \\
\text { Interval of the } \\
\text { Difference }\end{array}$} & & & \\
\hline & & & & & Lower & Upper & & & ) \\
\hline $\begin{array}{l}\text { Pair } \\
1\end{array}$ & $\begin{array}{l}\text { PreTest } \\
\text { Eksperime } \\
\mathrm{n} \text { - } \\
\text { PostTest } \\
\text { Eksperime } \\
\mathrm{n}\end{array}$ & $-58,95349$ & $\begin{array}{r}16,5 \\
3129\end{array}$ & $\begin{array}{r}2,521 \\
00\end{array}$ & $-64,04107$ & $-53,86591$ & $-23,385$ & 42 &, 000 \\
\hline $\begin{array}{l}\text { Pair } \\
2\end{array}$ & $\begin{array}{l}\text { PreTest } \\
\text { Kontrol - } \\
\text { PostTest } \\
\text { Kontrol }\end{array}$ & $-46,62500$ & $\begin{array}{r}15,6 \\
6425\end{array}$ & $\begin{array}{r}2,476 \\
73\end{array}$ & $-51,63467$ & $-41,61533$ & $-18,825$ & 39 &, 000 \\
\hline
\end{tabular}

Hasil uji hipotesis yang menunjukkan bahwa nilai sig. 2-tailed 0,00 $<0,05$ dengan nilai t-hitung > t-tabel yaitu 23,38> 2,01 yang berarti terdapat pengaruh signifikan pada pembelajaran TGT (Teams Games Tournaments) dengan media explosion box pada materi sistem ekskresi manusia terhadap hasil belajar siswa. Hal ini sejalan dengan penelitian lain bahwa penerapan pembelajaran TGT (Teams Games Tournaments) dapat meningkatkan hasil belajar siswa dalam ranah kognitif (Sulistyo, Eko, Mediatati, 2019).

Berdasarkan analisis nilai rata-rata post-test hasil belajar siswa terdapat perbedaan pada kelas ekperimen dengan kelas kontrol. post-test hasil belajar siswa pada kelas ekperimen adalah 81,51 dan post-test hasil belajar siswa pada kelas kontrol adalah 70,37. Dalam hal ini dapat diketahui bahwa post-test hasil belajar siswa kelas ekperimen lebih tinggi daripada kelas kontrol. Sehingga dapat disimpulkan bahwa pembelajaran TGT (Teams Games Tournaments) dengan media explosion box berpengaruh terhadap hasil belajar siswa pada materi sistem ekskresi manusia. Hasil penelitian ini didukung oleh penelitian Ayu Asih Wiranti tahun 2019 yang menyatakan bahwa penerapan model pembelajaran Teams Games Tournamenst (TGT) dapat meningkatkan proses pembelajaran dengan naiknya nilai rata-rata presentasi hasil belajar siswa (Ayu, 2019).

Selanjutnya pada penelitian lainterdapat peningkatan hasil belajar siswa yang diberikan perlakuan menggunakan pembelajaran kooperatif tipe teams games tournaments, dan peningakatan hasil belajar siswa yang diberikan pada model pembelajaran kooperatof tipe teams games tournaments lebih baik daripada pembelajaran konvensional (Muchtadi, 2013).

\section{SIMPULAN}

Berdasarkan analisis data penelitian dan pembahasan dapat disimpulkan bahwa ada pengaruh pembelajaran TGT (Teams Games Tournaments) dengan media explosion box pada materi sistem ekskresi manusia terhadap hasil belajar siswa kelas XI IPA Ma 
Al-Mukhlishin Batu Bara. Dengan nilai sig 2-tailed 0,00 <0,05 dengan nilai t-hitung > ttabel yaitu $23,38>2,01$.

\section{DAFTAR RUJUKAN}

Ayi, S. (2010). Model Pembelajaran Pakem dalam Pendidikan Jasmani Di Sekolah Dasar. Jurnal Penelitian Pendidikan, 11(1).

Departemen Agama RI. (2020). Al-Quran dan Terjemahannya. Jakarta: Lajnah Pentasihan Alquran.

Fitriya, N, dkk. (2019). Level Kognitif Literasi Berbantu Explosion Box Sastra Terhadap Kemampuan Menemukan dan Memahami Konsep Moral Siswa Kelas IV SD. Jurnal Pendidikan, 4(4).

Muchtadi. (2013). Pembelajaran Kooperatif Tipe TGT dan Konvensional Ditinjau dari Gender Pada Materi Operasi Pecahan di SMP. Jurnal Pendidikan Informasi dan Sains, 2(2), 2.

Sinamora, Hajriah, Hasibuan, \& Lubis. (2019). Pengaruh Penerapan Permainan Magic Box (Kotak Misteri) Terhadap Perkembangan Bahasa Anak Usia 5-6 Tahun di Ra Al-FAJAR Medan Denai. Jurnal Raudhah, 7(2), 97.

Sulistyo, Eko, \& Mediatati. (2019). Upaya Meningkatkan Hasil Belajar Siswa dalam Pembelajaran PPKn Melalui Model Kooperatif TGT (Teams Games Tournaments), $J P 2,2(2)$.

Syarifuddin, dkk. (2019). Guru, Mari Kita Menulis Penelitian Tindakan Kelas (PTK). Yogyakarta: Deepublish.

Tukiran, Faridli, \& Harmianto. (2017). Model-model Pembelajaran Inovatif. Bandung: Alfabeta

Ulfa, dkk. (2017). Efektivitas Model Pembelajara Kooperatif Tipe Teams Games Tournament dalam Keterampilan Menulis Bahasa Jerman Siswa Kelas XII IPA SMA Negeri 1 Botonompo Kabupaten Gowa. Jurnal Penelitian Pendidikan Insani, 20(1), 68 .

Yunus, W, dkk. (2017). Perbedaan Hasil Belajar Siswa yang Diajar Menggunakan Model Pembelajaran Teams Games Tournaments (TGT) dengan Model Pembelajaran Konvensional di Kelas XI Mia SMA Negeri 2 Pangkajene (Studi Pada Materi Pokok Asam Basa), Jurnal Chemica, 18(1).

Wiranti, A. (2019). Peningkatan Proses dan Hasil Belajar Matematika Melalui Model Pembalajaran Teams Games Tournaments (TGT) Siswa Kelas 5. Jurnal Ilmiah Pendidikan Matematika, 6 (1). 